\title{
Serum aldolase and phosphocreatine kinase in umbilical cord blood
}

\author{
MARGARET CHADD, O. P. GRAY, R. A. SAUNDERS, AND R. T. JONES \\ From the Department of Child Health, Welsh National School of Medicine, and the \\ Department of Clinical Pathology, Llandough Hospital, United Cardiff Hospitals
}

SYNOPSIS Aldolase was estimated in the cord blood of 81 newborn infants and phosphocreatine kinase in 87 infants. There is a wide range in the results, with some values falling in the range 8 reported in children with muscular dystrophy or of carriers of the disease. There is no correlation of the serum enzyme levels with the infant's birth weight. High levels of phosphocreatine kinase were $\subseteq$ found in infants of mothers with pre-eclamptic toxaemia. A single estimation of cord phospho- $z$ creatine kinase and aldolase is of little help in determining whether or not an infant has muscular dystrophy.

The enzymes aldolase and phosphocreatine kinase are useful aids to the diagnosis of muscular dystrophy (Sibley and Lehninger, 1956; Forster and Escher, 1961), as the serum levels of both enzymes are raised in affected children and may also be raised to a lesser degree in carriers (Leyburn, Thomson, and Walton, 1961 ; Richterich, Rosin, Aebi, and Rossi, 1963). A family which already possesses an affected child may wish to know whether a newborn baby is to be affected by the disease, and this question may be answered by a study of the infant's enzymes.

Phosphocreatine kinase, an intracellular enzyme, catalyses the reaction of creatine phosphate and A.D.P. to form creatine and A.T.P. It is abundant in skeletal muscle and to a much lesser extent in myocardium and brain. It is almost absent from other tissues and so haemolysis does not affect results. Serum levels are raised not only in muscular dystrophy, but also in hypothyroidism and cardiac infarction.

1:6-Diphosphofructoaldolase is an intracellular glycolytic enzyme found in cardiac and skeletal muscle, liver, and red cells. Haemolysis therefore raises serum levels. Its function is to catalyse the reversible splitting of $D$ fructose 1:6 diphosphate into equimolecular amounts of D glyceraldehyde-3phosphate and dihydroxyacetone phosphate. Serum levels are raised when cells are destroyed as in myocardial infarction (Volk, Losner, and Aronson, 1956), in muscular dystrophy and the myopathies (Schapira, Dreyfus, and Schapira, 1953), and in

Received for publication 6 July 1966. hepatitis (Sibley and Fleisher, 1954). There is little information available on normal values for newborn infants. Griffiths (1964) reported values of the phospho-creatine kinase in cord blood and the serum of male and female newborn infants, and showed the means and the ranges to be from two to about three times that of older children. The aldolase levels in $\triangle$ cord blood reported by Friedman and Lapan in 1958 are higher than in older children.

The present study determined cord blood levels of phosphocreatine kinase and aldolase in full-term and premature infants. Blood was collected from the umbilical vein at the delivery of the placenta.

\section{METHODS}

Aldolase was estimated by the colorimetric method of Sibley and Lehninger (1949) modified by Sigma (Technical Bulletin no. 750). Serum is incubated with buffered $\frac{7}{0}$ fructose 1:6 diphosphate in the presence of hydrazine which traps glyceraldehyde 3-diphosphate and di- $N$ hydroxyacetone. The protein is removed by trichloracetic acid, the triose phosphates are hydrolyzed by alkali at $N$ room temperature, and the trioses so formed are con- $\omega$ verted to osazones by $2: 4$ dinitrophenyl hydrazine. The $\sigma$ density of the osazones is read at $540 \mathrm{~m} \mu$, against a substrate-free blank similarly treated. The unit of activity is that amount of enzyme which splits $1 \mathrm{c} . \mathrm{mm}$. of fructose $\mathbb{E}$ 1:6 diphosphate solution per hour at $37^{\circ} \mathrm{C}$. A specimen ? showing any haemolysis was rejected. Phosphocreatine ${ }^{T}$ kinase was estimated by the spectrophotometric method $\frac{\vec{\Phi}}{\Phi}$ of Tanzer and Gilvarg (1959), which measures the rate of $\mathcal{\Phi}$ conversion of creatine and A.T.P. to creatine phosphate and A.D.P. by the enzyme in the presence of magnesium 
ions and glycine buffer at $p \mathrm{H} \mathrm{9 \cdot 0.} \mathrm{The} \mathrm{A.D.P.} \mathrm{produced}$ is reconverted to A.T.P. by phosphenol pyruvate and pyruvate kinase. The pyruvate formed is converted to lactate by the addition of lactic dehydrogenase and reduced nicotinamide-adenine-dinucleotide $\left(\mathrm{NADH}_{2}\right)$. The rate of decrease of optical density at $340 \mathrm{~m} \mu$ measures the conversion rate of $\mathrm{NADH}_{2}$ to NAD and hence phosphocreatine kinase activity. The unit is the International Unit of Biochemistry.

\section{RESULTS}

PHOSPHOCREATINE KINASE Eighty-seven cord bloods were tested for phosphocreatine kinase (Table 1); 38

TABLE I

RESULTS FOR PHOSPHOCREATINE KINASE

\begin{tabular}{lrlll}
$\begin{array}{l}\text { Weight of Baby } \\
(\mathrm{g} .)\end{array}$ & No. & Mean & Range & S.D. \\
\hline$-1,499$ & 1 & $2 \cdot 070$ & - & - \\
$1,500-1,999$ & 9 & $0 \cdot 729$ & $0-4 \cdot 24$ & $1 \cdot 352$ \\
$2,000-2,499$ & 9 & $0 \cdot 457$ & $0-2 \cdot 175$ & $0 \cdot 508$ \\
$2,500-2,999$ & 16 & 0.946 & $0-6 \cdot 16$ & $1 \cdot 476$ \\
$3,000-3,499$ & 31 & $0 \cdot 397$ & $0-1 \cdot 68$ & $0 \cdot 731$ \\
$3,500-3,999$ & 16 & $0 \cdot 323$ & $0-1 \cdot 68$ & $0 \cdot 453$ \\
$4,000+$ & 5 & $0 \cdot 158$ & $0-0 \cdot 336$ & $0 \cdot 141$
\end{tabular}

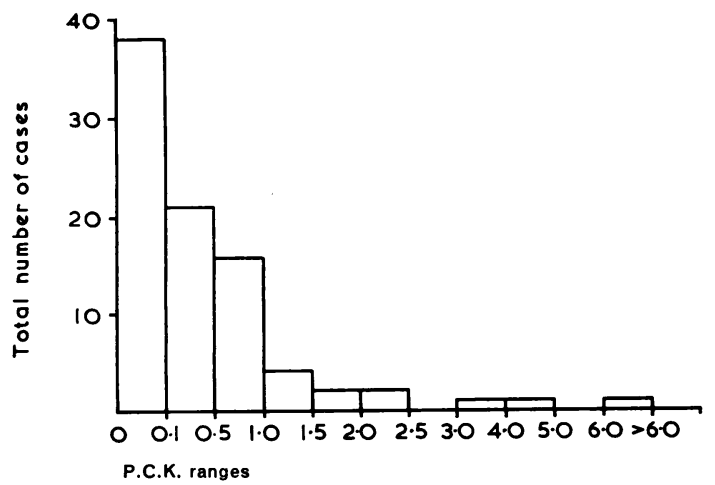

FIG. 1. Total cord phosphocreatine kinase results in the various ranges.

cord samples had no demonstrable activity and only 11 had levels over 1.0 unit. The majority of the cord serum values were less than 0.5 units (Fig. 1). Eight of the 11 children with levels over 1.0 unit were anoxic at birth, with Apgar scores of 5 or less. The mothers of all these 11 babies had pre-eclamptic toxaemia or toxaemia, three with severe hypertension. The placentae showed degeneration or infarction in nine. The two babies who were offspring of toxaemic mothers and were not anoxic at birth had normal plancentae. Analysis of the phosphocreatine kinase values of the various weight groups shows similar results except that there are slightly higher ranges in the lower weight groups (Table I and Fig. 2).

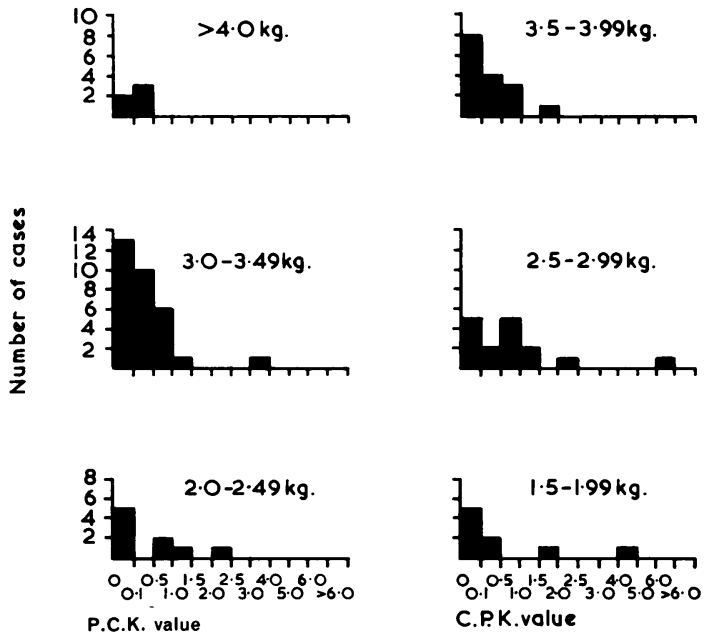

FIG. 2. Histograms showing number of cases and cord phosphocreatine kinase values in the various birth weight groups.

ALDOLASE Eighty-one infants' cord bloods were examined for aldolase levels. The results are shown in Figure 3. Analysis of the aldolase levels of the various weight groups showed that values were very similar in the different groups. The means lay between 15 and 30 (Table II and Fig. 4). The group of babies of toxaemic mothers who had high phosphocreatine kinase levels (over 1.0) had aldolase levels which were not raised.

\section{DISCUSSION}

PHOSPHOCREATINE KINASE These results appear to be lower than those reported by Griffiths (1964). The method which he used is based on different principles and gives results which are about four times higher

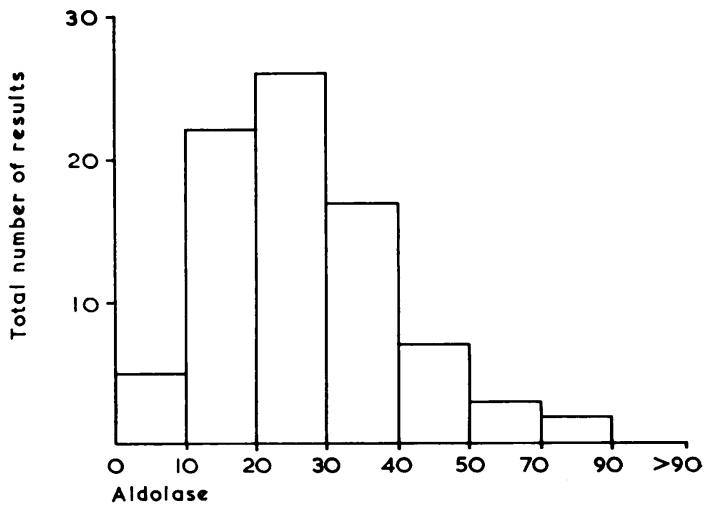

FIG. 3. Total aldolase results in the various ranges. 
TABLE II

RESUI.TS FOR ALDOLASE

\begin{tabular}{lrrrr}
$\begin{array}{l}\text { Weight of Infant } \\
\text { (g.) }\end{array}$ & No. & Mean & Range & S.D. \\
\hline$-1,499$ & 1 & 15 & - & - \\
$1,500-1,999$ & 9 & 27 & $14-41$ & $7 \cdot 375$ \\
$2,000-2,499$ & 12 & 16 & $3-34$ & $10 \cdot 20$ \\
$2,500-2,999$ & 13 & 26 & $3-62$ & $14 \cdot 39$ \\
$3,000-3,499$ & 25 & 22 & $10-48$ & $11 \cdot 14$ \\
$3,500-3,999$ & 15 & 30 & $10-76$ & $16 \cdot 65$ \\
$4,000+$ & 6 & 30 & $10-52$ & $15 \cdot 71$
\end{tabular}
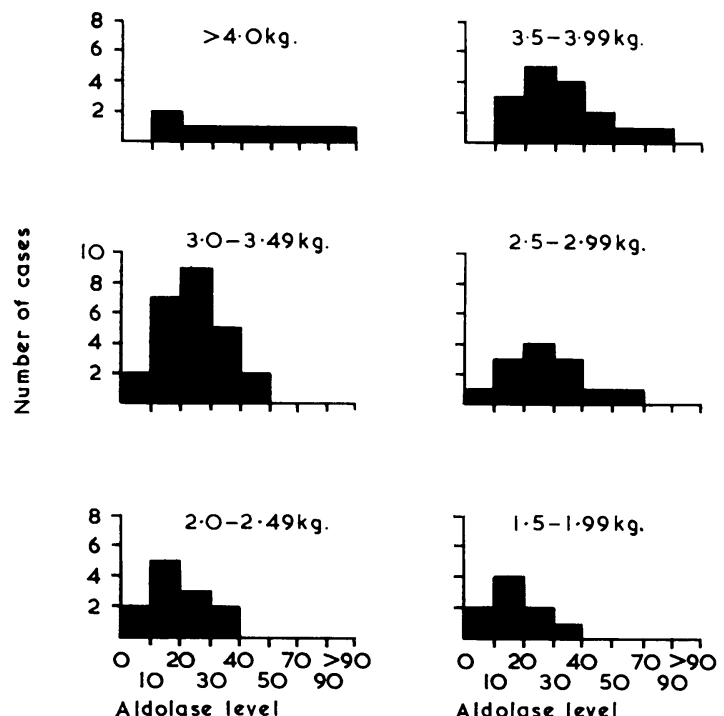

FIG. 4. Histograms showing number of cases and aldolase levels in the various birth weight groups.

numerically than the method used in the present study. This accounts for the fact that there were 38 babies in the present series with no detectable phosphocreatine kinase activity whereas Griffiths found some demonstrable activity in all his cases. Most of the cord blood levels are within the range of normal adults. Those infants who had results over 1.0 are within the range reported for carriers of muscular dystrophy (Richterich et al., 1963), but in view of the fact that the mothers of all these infants had preeclamptic toxaemia it is likely that the raised levels were related either to the maternal and placental condition, or alternatively to the intrapartum anoxic birth trauma which is known to have occurred in at least eight of the 11 babies. It is suggested, therefore, that when investigating the sibling of a patient with muscular dystrophy particular attention should be paid to the pregnancy, placenta, and birth. The finding of a high cord level suggests that the test should be repeated after an interval of time.

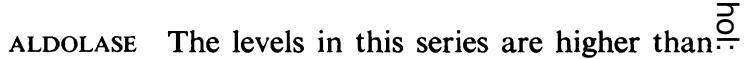
those in normal adults (Friedman and Lapan, 1958). $\overrightarrow{\vec{F}}$ These authors, using a modification of Bruns' (1954) method, reported a mean of 15.5 units with a range of $7 \cdot 2$ to 25.4 units (S.D. 5.7) in adult capillary blood. The venous blood samples were slightly lower (mean for normal men 14.3 and for normal women 12.3). However, they found higher levels in womenos at term with a mean of 19.6 units and a range of $7 \cdot 1 \overrightarrow{0}$ to 43.8 (S.D. 7.8). The infants in the present series have results which are lower than those found by Friedman and Lapan in cord blood where the range was 12.6 to 84.0 (S.D. 18.1). The mean and range of? their results in normal adults is about twice that $\overrightarrow{0}$ obtained by our method, which gives results of 3 to 12 units. Taking account of this, our results are slightly higher than those of Friedman and Lapan.응 The analysis of the aldolase results according to birth weight shows very little difference between the $\vec{z}$ groups. The levels found in the cord bloods are highero than those found in normal children and adults in this hospital (3 to 12 units). One other interesting finding is the high levels in apparently normal newborn infants, with no family history of muscular $\overrightarrow{0}$ dystrophy. The levels found are within the range of sufferers from muscular dystrophy. The fact that these normal babies had high levels makes cord? blood aldolase levels of no value in determining whether a newborn child is a sufferer from theo disease. These high levels may be a reflection of the maternal levels or of the high metabolic state of the newborn infant's glycolytic system. A furthero possibility is that the aldolase level may be raised by liberation of placental enzymes after the separation of the placenta from the maternal circulation.

We wish to thank Mrs. Ann Ackerman and Mrs. Cary를 Wilkinson for technical assistance, Miss Susan Bell foin secretarial assistance, Mr. R. Evans for preparing the figures, and Dr. T. E. Parry, consultant pathologist, for laboratory facilities.

\section{REFERENCES}

Bruns, F. (1954). Biochem. Z., 325, 156.

Forster, G., and Escher, J. (1961). Helv. med. Acta, 28, 513.

Friedman, M. M., and Lapan, B. (1958). J. Lab. clin. Med., 51, $745 \mathrm{~N}$ Griffiths, P. D. (1964). J. clin. Path., 17, 56.

Leyburn, P., Thomson, W. H. S., and Walton, J. N. (1961). Ann hum. Genet., 25, 41 .

Richterich, R., Rosin, S., Aebi, U., and Rossi, E. (1963). Amer. hum. Genet., 15, 133.

Schapira, G., Dreyfus, J. C., and Schapira, F. (1953). Sem. Hôp

Paris, 29, 1917.
Sibley, J. A., and Fleisher, G. A. (1954). Proc. Mayo Clin., 29, $591 \frac{}{1}$ -, and Lehninger, A. L. (1949). J. biol Chem., 177, 859. (1956). J. nat. Cancer Inst., 9, 203.

Tanzer, M. L., and Gilvarg, C. (1959). J. biol. Chem., 234, 3201. Volk, B. W., Losner, S., Aronson, S. M., and Lew, H. (1956). Amer. med. Sci., 232, 38. 